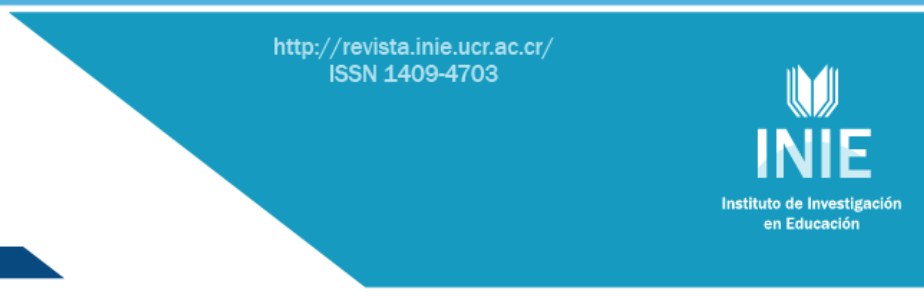

\title{
MARTÍN FIERRO PARA LA NIÑEZ ARGENTINA: LA PEDAGOGÍA DEL GAUCHO EN LA ESCUELA PRIMARIA
}

MARTÍN FIERRO FOR ARGENTINE CHILDREN: THE GAUCHO PEDAGOGY IN PRIMARY SCHOOL

\author{
Volumen 16, Número 2 \\ Mayo-Agosto \\ pp. 1-22
}

Este número se publicó el $1^{\circ}$ de mayo de 2016

DOI: http://dx.doi.org/10.15517/aie.v16i2.23932

Matías Emiliano Casas

Revista indizada en REDALYC, $\underline{\text { SCIELO }}$

Revista distribuida en las bases de datos:

LATINDEX, DOAJ, E-REVIST@S, IRESIE, CLASE, DIALNET, SHERPA/ROMEO, QUALIS, MIAR

Revista registrada en los directorios:

ULRICH'S, REDIE, RINACE, OEI, MAESTROTECA, PREAL, CLACSO 


\section{MARTÍN FIERRO PARA LA NIÑEZ ARGENTINA: LA PEDAGOGÍA DEL GAUCHO EN LA ESCUELA PRIMARIA \\ MARTÍN FIERRO FOR ARGENTINE CHILDREN: THE GAUCHO PEDAGOGY IN PRIMARY SCHOOL}

\section{Matías Emiliano Casas ${ }^{1}$}

Resumen: Las recurrentes apelaciones a la función patriótica de las escuelas argentinas establecieron los parámetros que contextualizaron la circulación de la cultura gaucha en las aulas a partir de la década del treinta. En este ensayo, la atención se focaliza en la utilización del Martín Fierro y las adaptaciones operadas sobre las características del personaje original para que resultara "maestro legítimo" de los niños escolares. También se abordan las actividades propuestas a partir de la literatura gauchesca en pos de ejercitar distintos contenidos. Desde las políticas educativas, la figura del gaucho resultaba un recurso fundamental para promover una serie de valores estudiantiles. Ese posicionamiento implicó determinadas reconfiguraciones al gaucho para que el otrora considerado matrero y bandolero sea reconocido ahora como docente moralizador y ejemplo de patriotismo.

Palabras clave: MARTÍN FIERRO, EDUCACIÓN, NACIONALISMO, GAUCHO, ARGENTINA

Abstract: Since the thirties, the patriotic role of education contextualized the gaucho circulation in the classroom. In this paper, we focus on the use of the Martin Fierro and the adaptations operated on the original character to build a "legitimate master" of schoolchildren. The use of gaucho literature to exercise different content are also addressed. From education policy, the gaucho was a key to promote a set of values in students. That role involved some reconfigurations to the gaucho, so that who was considered outlaw and bandit before, became now recognized as moralistic teacher and example of patriotism.

Keywords: MARTÍN FIERRO, EDUCATION, NATIONALISM, GAUCHO, ARGENTINA

${ }_{1}$ Historiador. Universidad Nacional de Tres de Febrero; Investigador del CONICET, Argentina; Université Paris Diderot, Francia.

Dirección electrónica: mecasas@untref.edu.ar

Artículo recibido: 21 de julio, 2015

Enviado a corrección: 4 de marzo, 2016

Aprobado: 31 de marzo, 2016 


\section{Introducción}

Las recurrentes apelaciones a la función "nacionalizadora" de las escuelas argentinas establecieron los parámetros que contextualizaron la circulación del gaucho en las aulas a partir de la década del treinta. El sistema educativo experimentó para esa época una revitalización de la enseñanza patriótica. La centralidad de la nación en el sistema educativo no había resultado una característica exclusiva de la Argentina. Como plantea Andrés Donoso Romo (2010), en el período que abarcó las últimas décadas del siglo XIX hasta la celebración de los centenarios en América Latina, el componente nacionalista de la educación fue un elemento común en toda la región. En efecto, desde comienzos del siglo $\mathrm{XX}$, las concentraciones urbanas y los incipientes procesos de industrialización latinoamericanos conllevaron la expansión del sistema educativo que pretendía abarcar, desde entonces, a los conjuntos poblacionales mayoritarios.

El tránsito hacia una educación más inclusiva convergió con la maquinaria simbólica que propulsó la misión patriótica de las escuelas. La apelación a la identidad nacional como contenido prioritario se explicaba desde las diversas crisis que atravesaron las sociedad del continente en las primeras décadas del siglo XX (Ansaldi, 2008). Ante las beligerancias y tensiones internas, los Estados-nacionales rápidamente advirtieron la imperiosa necesidad de un referente compartido para establecer lazos de identificación y solidaridad entre sus ciudadanos (Donoso Romo, 2010). Esa referencia se posó en el concepto de nación que, a su vez, era encarnizado por los próceres destacados desde las historiografías oficiales y representado por los emblemas iconográficos. Esa "liturgia patriótica" (Lvovich, 2004) se introdujo con fuerza en tanto bien supremo de una comunidad. La eficacia del mensaje radicaba en la plausibilidad de ofrecer la vida por ese "interés común" como ejemplo máximo de abnegación (Anderson, 1991).

Una serie de estudios da cuenta de la relevancia de la cuestión nacional en la época de los centenarios latinoamericanos (Fernández, 2006; Lampérière, 1995; Ortemberg, 2014). De hecho, en esa coyuntura, los gobiernos celebraron nacionalidades aún con contornos difusos y con disputas de soberanía candentes como el problema del Pacífico. Las reafirmaciones patrióticas emergían con vitalidad ante los plausibles conflictos. En Argentina, las políticas educativas dieron cuenta de la "urgencia patriótica". La expansión del mensaje fue congruente a la expansión de las escuelas. Como había advertido José Martí, el sistema educativo argentino había desarrollado un exitoso proceso de ampliación que se plasmaría con la ley 1.420, que decretó la enseñanza gratuita, laica y obligatoria: "En aquella lejana 
República [Argentina], con fuego y prisa generosos en ninguna otra de las nuestras igualadas, se oyen de todas partes [...] estas otras palabras de pase a otro mundo, y contraseña de la ciudadela nueva: bibliotecas y escuelas" (Martí, 1883, pp. 392-394).

Ese vigoroso sistema educativo acudió a la "pedagogía del centenario" en el transcurso de la década del treinta. El contexto político del país revitalizó las urgencias por cristalizar la identidad nacional. La crisis económica internacional había significado para Argentina la retracción de sus exportaciones, la reducción de puestos de empleo y la baja de salarios. La tensión social fue antesala del golpe de Estado que derrocó al gobierno democrático e inauguró un largo período de interrupciones militares en el país. Los militares que tomaron el mando del Gobierno se abocaron, en esos primeros años, a "restituir el orden" intensificando la intervención social. La desarticulación de los sindicatos, la persecución y deportación de comunistas y anarquistas -que en algunos casos incluyó el fusilamiento- reavivaron la animadversión hacia los activistas extranjeros. En los meses sucesivos al golpe se creó, en el seno de la Policía Federal, una Sección Especial de Lucha Contra el Comunismo. Además, en diferentes momentos de la década se aplicó la ley $N^{\circ} 4.144$, conocida como la ley de Residencia que había sido promulgada a comienzos del siglo y que permitía expulsar a extranjeros que perturbasen el orden público sin juicio previo ${ }^{2}$. En ese contexto, la circulación del imaginario gauchesco como referencia a lo autóctono y lo "argentino" fue incrementando a lo largo del período. Al mismo tiempo, las políticas del Consejo Nacional de Educación se concentraron en la consolidación de las efemérides patrias que conformaron el canon "litúrgico" de las escuelas primarias del país. El Día de la Bandera, el Día del Himno, el Día de la Escarapela, se incorporaron a las celebraciones escolares y sedimentaron las bases para la construcción de la identidad nacional (Amuchástegui, 1995; Escudé 1990; Puiggrós, 1995).

El objetivo de este estudio consiste en analizar cómo se integró esa cruzada nacionalista con la figura del gaucho en las escuelas argentinas. En el período de entreguerras se recuperó la representación del campesino pampeano como referencia identitaria para los argentinos. Ese proceso de reivindicación para un símbolo popular no constituía una operación exclusiva del país del plata. Como demuestra Ricardo Pérez, en México durante la década del treinta la tendencia de las políticas oficiales y las corrientes artísticas presentaron a estereotipos nacionales -como el charro- como símbolos de la

\footnotetext{
2 Sobre la conflictividad social y las políticas de gobierno en respuesta a la crisis durante la década del treinta, ver Béjar (1983). Con respecto a las políticas migratorias, ver un estudio analítico que, si bien abarca un período más extenso, reseña el incremento de obstáculos para la inmigración a raíz de la crisis económica, en Devoto (2001).
} 
mexicanidad (Pérez, 1999). Esas figuras aumentaron su visibilidad desde reconstrucciones arquetípicas que pretendían contener -y simplificar- las diversidades culturales de la nación. El gaucho argentino fue un ejemplo contundente de esas síntesis.

\section{Un gaucho para la nación}

Las máximas nacionalistas se complementaron con un proceso paralelo que transitaba la figura del gaucho. El "campesino bandolero", que había sido desestimado por las clases dirigentes que se ocuparon de la modernización del Estado en las últimas décadas del siglo XIX, fue reconfigurado en términos positivos. Los gobernantes conservadores, que llegaron al poder con el golpe de Estado de 1930, visualizaron en el gaucho un símbolo de reafirmación nacionalista, funcional para un contexto signado por el "temor" al cosmopolitismo (Cattaruzza y Eujanian, 2003). Desde esa perspectiva, se oficializaron festejos que recuperaron al arquetipo de la tradición nacional y lo consolidaron como emblema para la nación. El tipo gaucho ideal fue reconocido en el personaje literario Martín Fierro. El protagonista del poema resultó funcional, entre otros intereses, para cristalizar el "nacionalismo argentino".

El gaucho Martín Fierro apareció en 1872 por obra del escritor José Hernández. El autor había transitado una intensa participación político-militar en los años previos a la producción de su poema. De hecho, sus convicciones por la descentralización del poder económico concentrado en la provincia de Buenos Aires lo habían llevado a combatir a las tropas unitarias en diferentes ocasiones. Sus contiendas políticas determinaron su exilio, en particular su oposición a las políticas implementadas por los presidentes liberales Domingo Faustino Sarmiento y Bartolomé Mitre. En ese contexto de oposición y persecución se publicó El gaucho Martín Fierro, obra que se impuso, con el tiempo, como el libro épico de la literatura nacional. Promediando la década del veinte contaba con más de setenta mil volúmenes impresos y traducciones a diferentes idiomas (Corti Videla, 1926). Los trabajos que abordaron la obra como objeto de estudio lingüístico, histórico y socio cultural son abundantes y se siguen produciendo en la actualidad (Halperín Donghi, 1985; Míguez, 2005; Sarlo y Gramuglio, 1980; Stancanelli, 2009).

El poema de Hernández se compone de dos partes que fueron escritas y editadas con seis años de diferencia. En ese período, los cambios en la política nacional significaron la exoneración de José Hernández que se reincorporó a la arena política a partir de la derrota electoral de Bartolomé Mitre y la asunción de Nicolás Avellaneda a la presidencia. Las 
mutaciones en su situación personal redundaron en las modificaciones operadas a su protagonista (Halperín Donghi, 1985). En lo que posteriormente se conoció como La ida, el gaucho canta sus desventuras en la frontera y denuncia las situaciones de miseria que el desamparo provocaba en los soldados. La historia transcurre en las injusticias que determinaron su opción por volverse matrero, asesino, y vivir escapando de la policía. La primera parte finaliza con la decisión de marchar hacía las tolderías indígenas acompañado por su fiel amigo Cruz. La segunda parte del poema comienza con las vicisitudes de la vida entre los indios, pero se centra en las reflexiones que genera el personaje en torno a su vida de matrero. La ocasión de la redención de sus faltas -por la muerte del juez que lo acusabamodifica el derrotero de Fierro y se produce La vuelta desde una perspectiva conciliadora. El mensaje final del texto presenta un gaucho "rehabilitado" lo que sería un componente ineludible en su proceso de "canonización".

Desde finales de los años treinta, en la provincia de Buenos Aires primero y en todo el territorio nacional después, comenzó a celebrarse el Día de la Tradición. Cada 10 de noviembre, en homenaje al natalicio de José Hernández, los gobernantes, las asociaciones criollas, representantes de la Iglesia católica y otras instituciones, confluyen en la celebración de la vida gaucha. Junto con los accesorios del escenario campero, la iconografía nacionalista ornamentaba cada uno de los festejos (Casas, 2012). La efeméride se incorporó al calendario escolar, lo que propulsó el interés sobre el gaucho en las aulas argentinas. En este ensayo, la atención se focaliza en la circulación del Martín Fierro y las adaptaciones realizadas sobre las características del personaje original para que resultara "maestro legítimo" en las escuelas. Para eso, se analizan las publicaciones de las dos revistas principales de educación que tenían circulación nacional en el período: La Obra y El Monitor. También se relevan los libros de lectura de escuela primaria y las propuestas didácticas incorporadas en las publicaciones de tirada masiva como la revista Caras y Caretas.

\section{3. “¿Maula tiene diptongo?”: la literatura gauchesca en el aula}

Las actividades y proyectos áulicos fueron una de las vías de acceso de las representaciones del gaucho en la escuela. Algunas recomendaciones para el trabajo solo se remitían a indicar los fragmentos de textos a leer, pero no especificaban qué tipo de contenidos se trabajarían desde allí. Así, se estimulaba la lectura de diferentes relatos sobre la pampa, el ombú y el gaucho junto con las propuestas de recitado del Martín Fierro. En ocasiones se recomendaba trabajar la vida de la campaña pampeana de la segunda mitad 
del siglo XIX a partir de ese texto literario. En otros casos, la actividad consistía sólo en la copia y la lectura en voz alta. Además de ese material, que se difundía en las revistas educativas y en publicaciones de interés general, algunos manuales escolares complementaban el tratamiento de los textos con una guía de actividades para trabajar diversas temáticas, generalmente de lenguaje. El estudio del español a partir de la literatura gauchesca conllevaba la problemática de la "lengua popular criolla" que ameritaba aclaraciones para que no se reprodujera su utilización en el estudiantado de las escuelas.

En los últimos años de la década del treinta, la revista Caras y Caretas comenzó a incluir una sección denominada "el niño y la escuela" donde se publicaron diversas propuestas didácticas para que el cuerpo de docentes llevasen a las aulas. En el contexto de la década del treinta, la revista habría sido la publicación de interés general más importante de la Argentina. Esa relevancia se manifestaba no sólo en la densidad de sus ediciones semanales que rondaban las 150 páginas por número, sino también por la cantidad de ejemplares que en promedio superaban los 200 mil por semana (Rogers, 2008).

Varias de las actividades que presentaba Caras y Caretas remitieron a componentes del ámbito gauchesco, incorporados en las dinámicas de trabajo con diferentes objetivos. En 1937, se apelaba a fomentar en estudiantes la defensa de las tradiciones a partir de un texto sobre el ombú del escritor Javier de Viana. El autor era un periodista y novelista uruguayo que se había destacado por su actividad literaria en ambos márgenes del Río de la Plata. Miembro de una familia militar y hacendada, había comenzado sus estudios en medicina pero prontamente se abocó a producir obras de corte gauchesco y regionalista (Cantonnet, 1969). La inserción de la breve lectura en las clases se presentaba argumentada por la siguiente aclaración: "Días atrás, ante la impasible contemplación de medio centenar de personas, manos que casi se debiera clasificar de criminales abatieron un viejo ombú. Había allí varios niños." En pos de contrarrestar el "mal ejemplo" que habrían experimentado esos pequeños se promovía, como medida preventiva, el fragmento del autor tradicionalista que ponía de relieve "la agonía del árbol gaucho". Se explicitaba, como objetivo central de la lectura, la "defensa de la tradición criolla" que, de acuerdo con el diagnóstico de la revista, se veía "zaherida por el cosmopolitismo y por la ignorancia" (de Viana, 1937, p. 101). Como la mayoría de las intervenciones presentadas desde esa revista, la propuesta escolar se remitía a la reproducción de los fragmentos elegidos en sus páginas. Los textos no se encontraban complementados por actividades o cuestionarios para resolver en base a la lectura, se les 
delineaba un enfoque particular que, como en el caso del ombú, promovía una moraleja como conclusión.

Al año siguiente, las lecturas presentadas se clasificaban por cursos de la escuela primaria y, en cada edición, se publicaba una alternativa para trabajar en el aula. Las propuestas para los años mayores incluían breves biografías de autores reconocidos de la literatura argentina con algunos pasajes de sus escritos para reproducir en las clases. Las reseñas que se sintetizaban en esas páginas dejaban en evidencia la omisión de escritoras en el canon literario. En efecto, si bien Herminia Brumana y María de Villarino, entre otras, habían profundizado en temáticas gauchescas en varios de sus libros, desde Caras $y$ Caretas se concentraban en las plumas clásicas que se correspondían al género masculino. ${ }^{3}$ Para quinto y sexto año se presentaron fragmentos que involucraron al "gaucho". Cuando se analizó la trayectoria de Carlos Octavio Bunge -uno de los intelectuales argentinos más destacados de la época del centenario-, el texto seleccionado para ejemplificar "las virtudes de su pluma" expresaba: "el gaucho era fuerte y hermoso por su complexión física [...] recio y sarmentoso de músculos por los continuos y rudos ejercicios, agudo en la mirada de sus ojos negros." Allí, de modo tangencial dado que no remitía al interés primario de la lectura propuesta, se reproducía una interpretación "positiva" del gaucho que se encargaba, al final del texto, de disociar al sustantivo de la semántica peyorativa que había tenido en épocas anteriores (Caras y Caretas, 14 de mayo 1938, p. 128). Un enfoque similar se presentó con la propuesta de abordar la biografía de Martiniano Leguizamón, como "ferviente cultor de las tradiciones criollas y sincero argentino" (Caras y Caretas, 24 de setiembre 1938, p. 128) ${ }^{4}$. En la muestra de sus textos se extrajo un fragmento de su obra Alma nativa, donde se ponderaba el accionar de los jinetes en los "albores de la patria".

Las temáticas propuestas para primeros años de la escuela primaria no se correspondían a antologías de autores reconocidos sino que se presentaban como contenidos propios de cada año y se acompañaban con fotografías o ilustraciones. Para trabajar "La pampa", por ejemplo, se introducía el tema con un pasaje escrito por Juan Bautista Alberdi -pensador que inspiró la Constitución Nacional sancionada en 1853- que exaltaba a la región como "baluarte de la independencia" y a los gauchos como "los primeros soldados de la gesta". Luego, el autor hacía una clara referencia a la influencia de los

\footnotetext{
${ }^{3}$ Las dos escritoras señaladas eran reconocidas en los ámbitos tradicionalistas. El caso de Herminia Brumana será retomado más adelante en este artículo. Ver María de Villarino (1957).

${ }^{4}$ Martiniano Leguizamón se destacó por su prolífera producción en materia criollista. Su escrito más reconocido fue la producción dramaturga titulada Calandria que narraba la "adaptación" del gaucho "perseguido" y su transformación en "gaucho trabajador".
} 
"extranjeros laboriosos" que habrían convertido a esas llanuras en "el granero del mundo". En un apartado, una foto de un gaucho con su caballo (Figura 1) antecedía su "definición":

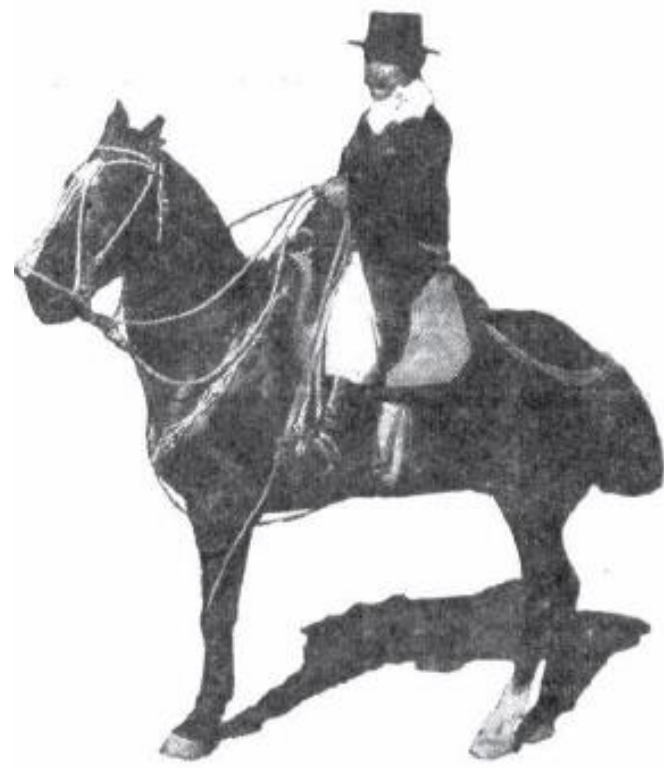

Figura 1. Caras y Caretas (4 de junio de 1938, p. 131)

"por lo general, se mantuvieron respetuosos de la autoridad, morales en sus costumbres y honrados en sus negocios" (Caras y Caretas, 4 de junio 1938, p.131). Esa era la perspectiva sostenida para interpretar la participación de los gauchos en el pasado nacional. En las líneas promovidas para tercer grado, se concluía: "[el gaucho] fue hombre libre y engrandeció al país trabajando en las faenas que, como las ganaderas, requieren hombres libres, fuertes e íntegros" (Caras y Caretas, 4 de junio 1938, p. 131). En otra de las publicaciones de la sección "el niño y la escuela" se retomaba la ligazón entre los gauchos y el proceso independentista a partir de la figura del General Martín Güemes. Allí se resaltaba el accionar del caudillo del norte y su montonera de gauchos para la defensa del territorio frente al avance realista. La lectura era acompañada por un anexo que presentaba la siguiente fotografía (Figura 2): 


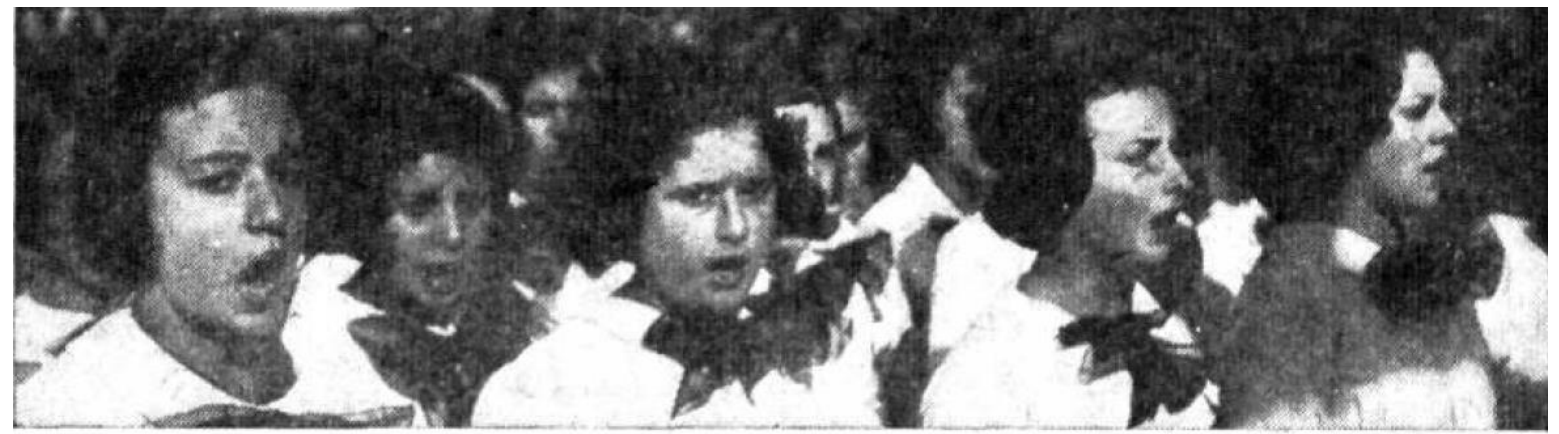

\section{HAY QUE CANTAR EL HIMNO}

Figura 2. Caras y Caretas (25 de junio de 1938, p. 154)

La imagen de las alumnas que interpelaba desde su título, se completaba con la exhortación: "Muchacho: Dentro de pocos días se iniciarán los festejos del Nueve de Julio [efeméride que conmemora la proclamación de la independencia argentina en 1816] No te limites a escucharlo [el himno] mientras lo ejecutan las bandas y orquestas. ¡Cántalo y hazlo cantar por cuantos te rodean!" (Caras y Caretas, 25 de junio, 1938, p. 154). Así, el tratamiento de los combates de Güemes y sus gauchos parecía ser la introducción indicada para reafirmar las normativas nacionalistas a cumplir para el segundo grado.

La revista de educación La Obra también propuso distintas lecturas relativas a lo gauchesco para su trabajo en el aula. Esa publicación, que se había fundado en la década del veinte, se ocupó en defender las condiciones labores de los docentes, cuestionando los salarios, los regímenes de licencias, la infraestructura escolar, etc. (Finocchio, 2009). En referencia a la presentación de actividades, La Obra ofrecía consignas concretas pensando en su aplicación directa a partir de la mediación del docente. En 1940, para trabajar en la materia lenguaje, se reprodujeron los versos de la primera parte de Santos Vega, el poema de Rafael Obligado que relataba la historia de un payador gaucho.

La leyenda de Santos Vega narraba la historia de un gaucho cantor que se destacaba en la capacidad de repentización e improvisación de versos, generalmente cantados a la sombra de algún ombú. La tradición popular contaba el ocaso de su vida a partir de una derrota en el contrapunto frente a un rival desconocido que varias versiones identificaban como el diablo mismo, dado que se consideraba el único capaz de vencerlo.

A continuación del texto, en La Obra se incluía una serie de recomendaciones para las personas docentes donde se confirmaba esa producción literaria como un elemento autóctono, "Ileno de nuestras tradiciones y del alma de nuestra tierra". Si bien se precisaba 
que el trabajo de ese pasaje -perteneciente a la primera parte titulada "El alma del payador"resultaba obligatorio para sexto grado, se aconsejaba la lectura completa del poema que debía constituir una fiesta para el alumnado. Luego, se establecía la actividad a realizar con el texto: "los niños lo copiaran en sus cuadernos de trabajo con toda corrección. Como no será posible que lo hagan en una sola clase, convendrá que dejen el espacio reservado para continuar en la primera oportunidad" (La Obra, 10 de junio 1940, pp. 282-283). Además de proponer la copia textual de los fragmentos publicados, la editorial de la revista fomentaba su memorización: "A pesar de que el programa indica que no se exigirá la recitación de más de cincuenta versos, nosotros nos inclinaríamos a que se la estudie íntegramente" (La Obra, 10 de junio 1940, pp. 282-283). En esa misma línea, otra propuesta didáctica cuestionaba la lectura fragmentada del Martín Fierro en las aulas: "el Martín Fierro hay que leerlo en toda su extensión, porque sólo así es posible apreciarlo en toda su grandeza" (La Obra, 10 de octubre 1945, p. 658). De ese modo, la partición del poema en estudios secuenciados solamente sería aceptada cuando la persona docente supliese, con su idoneidad, los versos faltantes con una síntesis apropiada para el grupo de estudiantes.

Los fragmentos del poema de José Hernández eran incluidos para trabajar diversos pasajes de la historia nacional del siglo XIX, como la "conquista del desierto". En ese caso se proponía analizar "la acción civilizadora del ejército" que había exterminado la población nativa en búsqueda de tierras cultivables. Entre las explicaciones que pretendían legitimar la expansión de la frontera se le dedicaba un espacio considerable a los malones indígenas que "amenazaban" a los colonos. Según las líneas de trabajo propuestas los "salvajes" eran la principal dificultad que encontraban los pobladores y el ejército para asegurar la "soberanía nacional". Esa construcción se apoyaba con la lectura de varias estrofas del Martín Fierro: "Es guerra cruel la del indio / porque viene como fiera; / atropella donde quiera / y de asolar no se cansa" (Hernández, 1879, cap. 4). El panorama presentado por José Hernández se complementaba con una recomendación para el cuerpo de docentes: "Imagínese el lector el cuadro horrible que representaba al malón, y haga notar a los escolares el sacrificio de los primeros pobladores de nuestras pampas" (La Obra, $1^{\circ}$ de noviembre 1951, pp. 458-459).

Otro canal de circulación que tenían los fragmentos de las obras gauchescas reconocidas eran los libros de texto que incorporaban su lectura, también de modo parcializado. El libro Clarinadas, para quinto grado, reproducía los versos de Santos Vega y de Martín Fierro, pero sin realizar alusiones al tratamiento de los escritos (García, 1957). A 
diferencia de las recomendaciones esbozadas en La Obra, las lecturas presentadas no prescribían su análisis ni las actividades a realizar a partir de ellas, pero contribuían, del mismo modo, a la reproducción del imaginario gauchesco en las aulas.

Otros manuales escolares presentaban diferentes propuestas pedagógicas para abordar contenidos disciplinares desde la figura del gaucho. En Canto al trabajo, un libro de lectura para cuarto grado, se difundía un fragmento del poema Lázaro, del escritor Ricardo Gutiérrez, que describía las características del "gaucho" ${ }^{5}$. Luego de la lectura de los versos se incluía un breve glosario para trabajar el significado de palabras desconocidas con el estudiantado. Por último, a partir de una ilustración se presentaba como consigna: "tema de composición y conversación: el gaucho argentino" (de Millán, 1940, p. 105). El dibujo que lo mostraba en la llanura de la pampa con un lazo en la mano, mirando hacia el horizonte, complementaba la reseña del poema como disparador para elaborar una redacción sobre la temática. En ese caso, el gaucho resultaba un recurso para trabajar contenidos desligados de la historia y de la interpretación de su figura. En la misma línea, el libro Brisas promovía el análisis de familias de palabras a partir de una lectura sobre el gaucho (Escuelas Pías Argentinas, 1940). Ambos textos escolares evidenciaban una funcionalidad que trascendía los caracteres particulares de la representación que se ponía en juego. Las narraciones sobre los gauchos -fuesen soldados, valientes, rebeldes, unitarios o federales- facilitaban el trabajo sobre contenidos específicos de la enseñanza del lenguaje. La particularidad del estudio a partir de la literatura gauchesca -a diferencia de otras temáticas que también se utilizaban como puerta de acceso para ejercitar diversos contenidos- radicó en las "correcciones" que se le realizaban a la "lengua popular criolla" en pos de evitar su reproducción.

El libro de lecturas para primer año de la escuela secundaria, Autores modernos, fue un exponente fundamental para analizar el abordaje de contenidos desde textos de la literatura gauchesca. La edición publicada en 1943 incorporaba un cuestionario gramatical y una serie de notas explicativas para cada fragmento propuesto. El autor era el profesor de Letras René Bastianini quien fue rector del Colegio Nacional Bartolomé Mitre y especialista en la historia de la literatura española (Mantovani, 2012). Para analizar el Santos Vega, se transcribían cinco páginas de la obra. El texto estaba introducido por una síntesis de la trama que la presentaba como condensadora de "toda la poesía de la pampa". En notas a pie de

\footnotetext{
${ }^{5}$ Ricardo Gutiérrez era un médico y escritor argentino del siglo XIX que también participó de las contiendas militares a favor de las tropas unitarias que defendían la centralidad de Buenos Aires y en la guerra del Paraguay. Sobre su trayectoria, ver Casais (2008).
} 
página se incluían las preguntas y consignas para que cada estudiante resolvieran. Se trabajaban, así, cuestiones relativas al significado de las palabras, por ejemplo buscar la "etimología de bulla”, casos de diptongo, como “¿Hay diptongo en maula?” -palabra que en lenguaje coloquial gauchesco significaba "tramposo"-, y la correcta pronunciación de palabras. Además de las actividades, en esas notas se incorporaban aclaraciones "correctivas" de la lengua popular con afirmaciones como: "Modo popular de decir. En lengua culta sería medio turbada" (Bastianini, 1943, p. 58). Algunas definiciones similares aparecían en el abordaje de la obra Don Segundo Sombra.

La novela, publicada en 1926, describe la historia de un joven que transita la pampa con su "padrino" y experimentado consejero, el viejo gaucho que había sido inspirado en un habitante de la campaña bonaerense llamado Segundo Ramírez, realizando labores de peón en diversas estancias. La trama concebida por Ricardo Güiraldes presenta una figura "moralizadora" del gaucho que desde su aparición en el relato va construyendo una versión edulcorada de aquellos domadores de la pampa bravíos y justicieros. La primera intervención del legendario Don Segundo es definida por la negación a la pelea ante los avances de un habitué de la pulpería. Con la posibilidad de rematarlo en su favor, el gaucho decide perdonarle la vida al matón y devolverle los retazos de su facón. Había llegado al pueblo en busca de trabajo. Como testigo de esa situación, el niño quedó cautivado por la imagen de Sombra y comenzó un proceso de acercamiento que concluiría con aventuras conjuntas y estrecha amistad (Güiraldes, 1926).

En la introducción del texto presentado en Autores Modernos se hacía explícita la representación de un gaucho templado, que sabría sostener la calma en situaciones límites y se remarcaba esa "virtud" a partir de los fragmentos reproducidos. Las actividades propuestas en ese caso se focalizaban en la ortografía y el análisis sintáctico de las oraciones. Además se estudiaba la conformación de metaplasmos y se definían determinadas expresiones como "Vi a: Voy a" (Bastianini, 1943, p. 212).

La señal de alerta más contundente para docentes que abordarían los textos promovidos en el manual se presentaba en relación a un cuento de Fray Mocho -escritor costumbrista y director de la revista Caras y Caretas- titulado "Después del recibo". La mayoría de las consignas para ese fragmento apuntaban a reconocer y develar los usos "vulgares" de la lengua. Como instancia previa a la presentación de esas actividades se prevenía: "Todo este cuento está escrito en lengua popular criolla, circunstancia que impone deformaciones ortográficas, síncopas, apócopes, cambios de acentos, etc. que será 
necesario destacar en cada caso" (Bastianini, 1943, p. 218). El destaque se correspondía a la pretensión de identificar esos términos como palabras vetustas e "incorrectas" que debían ser en primer lugar reconocidas y luego corregidas en la resolución del alumnado. En esos casos, donde se centralizaba la enseñanza en las características del lenguaje, las evocaciones al gaucho y la tradición sufrían la mediación escolar ${ }^{6}$. Es decir, así como se esbozaban recomendaciones que apuntaban a silenciar determinados componentes de su coyuntura social y económica, se intervenía, también, sobre su modalidad para expresarse. Si bien los contenidos de las lecturas apuntaron a destacar elementos "positivos" de su figura, la "lengua del gaucho" no resultaba un "atributo" a exaltar por las instituciones escolares. Por el contrario, como se verá en la propuesta de forjar en Martín Fierro un modelo de conducta, el lenguaje gauchesco ameritó sucesivas aclaraciones y rectificaciones.

\section{El maestro Martín Fierro}

Los usos de la literatura gauchesca en la escuela primaria argentina no constituían una novedad para el período aquí estudiado. Sin embargo, la confluencia del fervor nacionalista y el vigor que había obtenido la representación del gaucho como símbolo de la argentinidad significó la revitalización de esas temáticas. En ese contexto, Martín Fierro se puso al servicio de la construcción de un "gaucho moralizador" que se propuso, principalmente, desde las publicaciones escolares. Al mismo tiempo, algunos escritos tradicionalistas habían reparado en la "virtud" pedagógica del gaucho e incentivaban una mayor presencia de sus reflexiones en las aulas. Como se verá aquí, varios libros de lectura para estudiantes de primaria incorporaron fragmentos que reproducían "los consejos de Martín Fierro". La condensación de esas voces elaboraba un "gaucho" modelo y ejemplo para el alumnado. A partir de: omisiones, ya que varios pasajes de su vida quedaban silenciados en los filtros; justificaciones, sobre todo en lo referente al nivel educativo de los "gauchos"; y adaptaciones, que rozaban la tergiversación, Martín Fierro se constituía como rector de la moralidad.

El autor tradicionalista Elbio Bernárdez Jacques, uno de los escritores de mayor difusión en las asociaciones criollas de la década del cuarenta, propuso en su libro Fisonomías gauchescas, fomentar la lectura del poema de Hernández en lo que significaría

\footnotetext{
6 Otros ejemplos de correcciones a la lengua gauchesca en el seno de la institución escolar se advierten en las actividades propuestas para abordar fragmentos de Don Segundo Sombra y de Martín Fierro Bordato y Rivero (1943). En una publicación del Ministerio de Educación de la provincia de Buenos Aires que se repartía de modo gratuito en las escuelas se plasmaba de modo contundente las correcciones gramaticales al estilo gauchesco. Ver, Revista de Educación, Año III, número 6, junio de 1958, pp. 523-5326.
} 
una práctica de "robustecimiento de la nacionalidad": "Puede más el Martín Fierro que muchos textos de historia [...] pues aquél es la historia real y viviente de nuestro pueblo" (Bernárdez Jacques, 1945, p. 184). La postura de Jacques encontraba correlato en otros escritores contemporáneos. La docente Herminia Brumana -uno de los exponentes relevantes del feminismo argentino- proponía: "A mano tiene el maestro, en el propio Martín Fierro, el molde ideal para el metal que funde, y no perdiéndolo de vista es como podrá realizar su tarea hasta lograrlo honrado e (sic) cumplido" (Brumana, 1939, p. 242). La labor primaria, según se esbozaba en el texto, era conformar infantes conscientes de los derechos y deberes de "un argentino" (Brumana, 1939, p. 242). Para ese objetivo se proponía al gaucho Fierro como maestro. En la adhesión al poema de Hernández y su reproducción en las aulas estaría la clave para que los docentes y las docentes pudiesen cumplir con su tarea de forjar niñas y niños "responsables y solidarios patriotas".

En los libros de lectura se contribuyó a la "metodología didáctica" reseñada, en tanto varios textos incorporaron al gaucho Fierro en el rol de consejero. El libro Motivos americanos, editado para quinto grado, era presentado con una nota a las maestras y los maestros donde se posicionaba como un "auxiliar oportuno para desarrollar las clases". La autora era Juana Caso de Sedano Acosta, profesora que había ejercido como directora de la Escuela Normal $n^{\circ} 6$ de maestras ubicada en la Capital Federal. En su introducción, se dejaba constancia del plan estratégico de incorporación de lecturas, no desde una lógica de yuxtaposición sino más bien desde una secuenciación progresiva para facilitar la comprensión del estudiantado. Desde esa perspectiva se incluían tres páginas tituladas "Consejos de Martín Fierro" que compilaban una variada selección de versos acompañada de una pequeña ilustración. La inserción de los fragmentos no involucraba ninguna propuesta de actividad más allá de su lectura en clase.

En el libro de lectura para sexto grado denominado República, se le otorgó un tratamiento particular a las recomendaciones de Martín Fierro. Allí, se incorporó un texto introductorio con el análisis de la trama del poema estableciendo conexiones entre las etapas que había atravesado el gaucho, y las principales medidas gubernamentales que fueron delimitando sus coyunturas. El protagonista era definido como "verdadera encarnación del pueblo, arquetipo de la llanura argentina" (Darnet de Ferreyra, 1957, p. 203). Además, se le atribuía una serie de "cualidades" que parecían "legitimar" su recomendaciones posteriores: "Son sus rasgos característicos el valor en la acción y el ingenio en el habla [...] una honda capacidad para el amor, la amistad, y el patriotismo; un 
sentimiento tan profundamente cristiano" (Darnet de Ferreyra, 1957, p. 203). Desde ese enfoque se incluyeron siete páginas de consejos introducidas por una ilustración que mostraba al gaucho, con un mate en la mano, preparado para comenzar su alocución frente a sus tres hijos (Darnet de Ferreyra, 1957).

En el texto escolar Tierra pobre...tierra rica, quizá más sugerente que las advertencias que se incorporaban era la ilustración del gaucho mirando fijo hacia los receptores del mensaje, como se observa en la Figura 3:

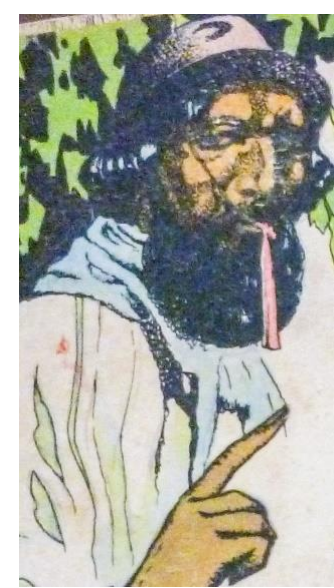

Figura 3. Guillermina Pougens de Martínez (1942, p. 117)

El dibujo lo representa con el dedo índice de su mano derecha levantada en evidente alusión a quien se dispone a prescribir una serie de recomendaciones. Ese efecto matiza un rostro curtido que componía una imagen poco amistosa, quizá, para la niñez de la escuela primaria. La rigidez del gaucho se construye apelando a la experticia. Su legitimidad parece radicar en el trayecto recorrido. De hecho, ya no posee guitarra ni caballo pero sí se presta a esbozar los consejos esperados. El contraste entre su pañuelo celeste y su camisa blanca conforma los colores patrios. Desde su voz se exaltaría esa evocación. De ese modo, a partir de la contundencia del dibujo se pretendía convocar la atención del estudiantado de cuarto grado (Pougnes de Martínez, 1942). Como se mencionó anteriormente, en Clarinadas, para quinto grado, también se incorporaron los "consejos de Fierro", pero en un espacio complementario al tratamiento de la biografía de José Hernández (García, 1957). Para la inserción de las máximas sobre la amistad o la unidad de los hermanos no se realizaba ninguna introducción ni intento de justificar la atribución de la palabra al gaucho. A modo de epílogo sobre el recorrido literario del autor, aparecían los fragmentos de Fierro sin mediar presentación ni aclaraciones. 
El trabajo con las enseñanzas del gaucho tuvo su propuesta más acabada en una publicación de El Monitor de la Educación Común, órgano del Consejo Nacional de Educación. En 1946, se presentó con el título “El refranero de Martín Fierro” una recopilación de glosas para el estudiantado. El artículo constituye la expresión más elaborada en tanto su autor, Ismael Moya, realizó una minuciosa adaptación y reinterpretación de los versos seleccionados para favorecer su comprensión. Los mensajes de Fierro fueron "decodificados" por Moya, quien era profesor de Letras y folclorista. Además, tenía un vínculo directo con las agrupaciones tradicionalistas y participaba recurrentemente en las celebraciones del Día de la Tradición. Era identificado como un exponente de los "gauchófilos", cuestionados por algunos autores académicos contemporáneos por promover la leyenda "gauchesca", más basada en relatos que en fuentes y datos concretos (Coni, 1945). La lectura de Moya comenzaba: "Niño: he aquí seleccionados para ti refranes y dichos de mucha enseñanza contenidos en el poema admirable que todo argentino debe conocer" (Moya, 1946, p. 51). Luego de posicionar al texto como una obra imprescindible para la identidad argentina, el autor retomaba las aclaraciones sobre la "lengua gauchesca". En este caso, se explicitaba la función escolar para eliminar la pervivencia de esas expresiones: "El rol de la escuela primaria, desde hace años, ha sido muy eficaz para adecuar el decir de las gentes de la campaña a las formas que consagran las reglas gramaticales vigentes" (Moya, 1946, p. 51). Para continuar con esa línea, Moya advertía cada palabra con una llamada y confirmaba su correcta escritura y pronunciación.

Luego de las aclaraciones gramaticales, se iba construyendo una operación que, al analizarla, remitía a otras tentativas de caracterizar al "gaucho". Por la metodología empleada, que consistía en la cita de determinados versos y la continua reinterpretación en orden a los intereses del autor, y por los componentes puestos de relieve, el "gaucho consejero" que se vestía de maestro se conjugaba con su representación como católico y soldado patriota, sostenido principalmente desde sectores de la Iglesia y las Fuerzas Armadas. De hecho, las apelaciones a elementos religiosos y nacionalistas fueron un denominador común de las interpretaciones "bajadas" para la niñez. Como anticipo de lo que se reiteraría en las veinte páginas que ocupaba el artículo, la primera reinterpretación se basaba en el canto de Fierro que expresaba: "Nadie me puede quitar / aquello que Dios me dio; Lo que al mundo truje yo / del mundo lo he de llevar" (Hernández, 1879, cap. 2). Esos versos eran ligados a la divina providencia y se recomendaba: "Debes esforzarte, niño mío, 
para mantener esos bienes de Dios y hacer que ellos fructifiquen en favor de la patria" (Moya, 1946, p. 52).

En torno al nacionalismo, las afirmaciones a partir de los cantos del gaucho operaban en un doble sentido. Por un lado, apuntaban a inculcar la noción de patria como "bien supremo" de toda la ciudadanía y, por otro lado configuraban al gaucho como modelo en ese interés colectivo. Desde esa perspectiva, cada progreso individual de los alumnos y las alumnas estaría correspondido en el desarrollo de la nación. Como el gaucho que habría sufrido grandes penurias y peligros para alcanzar el "don" de la libertad y darlo a la patria, al niño y a la niña se le solicitaba: "No desmayes por las dificultades que se te presenten en el estudio [...] Sé fuerte, trabaja. Lucha; gana el laurel para la Patria. Recuerda siempre las sencillas palabras del gaucho Martín Fierro que son la transparencia de una verdad eterna" (Moya, 1946, pp. 62-63). En efecto, las "palabras del gaucho" estaban veladas por la interpretación de Moya. La lección señalada no involucraba la voz directa de Fierro que contenía la "verdad eterna", sino que se utilizaba un verso del poema -disociado de la enseñanza sobre las dificultades en el estudio- como simple disparador para introducir la reinterpretación del folclorista.

La referencia a los elementos religiosos se construyó con las mismas herramientas. Desde vagas alusiones que mencionaban la "fuerza del cielo" y el destino del hombre o a partir de remarcar determinadas cualidades del gaucho como la generosidad, se insertaban evocaciones a Dios, su omnipotencia y la sumisión ante su voluntad. Así, se fomentaba la práctica de buenas conductas, confirmando la recompensa: "Dios bendecirá tu mano" (Moya, 1946, p. 65). En ocasiones, como cuando se motivaba la amistad, se incluían citas bíblicas para confirmar el carácter religioso de las expresiones de Martín Fierro. Las palabras del gaucho, más los conceptos católicos, le otorgaban una mayor contundencia a la enseñanza que se explicitaba al final de cada interpretación. En ese caso, la cita de Eclesiastés que equiparaba a un amigo con un tesoro, introducía la conclusión del autor: "Desde niño, cultiva el afecto de tus compañeros. Acércalos a tu espíritu. Ayúdalos; se leal y justo con ellos" (Moya, 1946, p. 65).

Las recomendaciones del "gaucho consejero" involucraban múltiples aspectos como: el valor de la familia, el ahorro, el respeto a los ancianos, la disciplina, la esperanza en Dios, la aberración al alcohol, etc. Sin embargo, una "virtud" aparecía recurrentemente y se encontraba ligada al desempeño escolar de la niñez. Para eso, nuevamente se extrapolaban versos de Fierro -expresados en otras circunstancias que nada tenía que ver con las 
instituciones escolares- y se los "ajustaban" a los intereses de la escuela. Por ejemplo, el canto "Y naides [sic] se muestre altivo / aunque en el estribo esté, / que suele quedarse a pie / el gaucho más alvertido [sic]" era interpretado y dirigido hacia el niño en los siguientes términos: "Muchas veces habrás estado a punto de gritar alborozado: ¡Ya es mío el sobresaliente! ¿Quién sabrá mejor que yo las lecciones del día? Y sin embargo, el olvido de una fecha, de un río, de una montaña, fueron los causantes de que no alcanzaras la palma." (Moya, 1946, pp. 52-53). Otro de los versos asociado al estudio de las lecciones era: "Cuando un hombre está en peligro / no debe tener confianza". El "peligro" era ligado a la situación de examen que implicaba dar cuenta de algún contenido trabajado en las clases. Desde ese enfoque, se recomendaba: "El gaucho amigo te enseña que en las horas de peligro no debes ser tan confiado que menosprecies los factores adversos. Muchos niños suelen descuidar algunos aspectos de su lección, confiados en que a la hora del examen, podrán desempeñarse con éxito" (Moya, 1946, p. 56).

Más allá de las forzadas relaciones, la "legitimidad" del gaucho para presentarse como erudito en cuestiones educativas necesitó algunas aclaraciones que Ismael Moya se ocupó de explicitar. Las explicaciones pretendían argumentar cómo el protagonista "recomendaba" la sumisión a las maestras y los maestros cuando no había transitado los procesos de escolarización: "El gaucho no tuvo escuela primaria donde instruirse, por eso ignoraba muchas nociones. No fue culpa suya, ya lo sabemos." (Moya, 1946, p. 70). Desde allí, se intentaba revalorizar las condiciones coyunturales que permitían la inserción de la niñez en las escuelas. Se consolidaba, entonces, una representación del gaucho construida a partir de un Martín Fierro reinterpretado. Los silencios sobre sus primeras aventuras como matrero y las adaptaciones de sus versos a intereses educativos, permitían establecerlo como modelo para el desempeño escolar de los niños de las escuelas primarias. La construcción de Moya, que se complementaba con la circulación en los libros de lectura, daba como resultado un "gaucho consejero" que, si bien se focalizaba en las actitudes ante el estudio, ponderaba el amor a la patria y el temor de Dios como "virtudes" inherentes a los estudiantes y las estudiantes de Argentina.

\section{A modo de conclusión}

Los continuos llamados a la enseñanza patriótica, que se manifestaron con énfasis en los años treinta y se reprodujeron a comienzos de la década del cuarenta, sumado a la creciente preocupación por la educación en las zonas rurales, convergieron como factores 
posibilitadores de la reproducción de la figura del gaucho en las escuelas. De ese modo, al proceso "reivindicatorio" que atravesaba canales políticos y despertaba el interés de diversas instituciones se le agregaba el marco educativo que encontraba en el "gaucho" un recurso para fortalecer su discurso patriótico. La preocupación por cristalizar la nacionalidad era un denominador común en la región. Como se señaló aquí, la recuperación de un arquetipo tradicional tenía su correlato en otros países de América a partir de la consolidación de emblemas e íconos nacionales.

En Argentina, las resoluciones del Consejo Nacional de Educación confirmaron la funcionalidad del gaucho y regularon su conmemoración cada 10 de noviembre. El estudio de los libros de lectura y de las revistas educativas da cuenta de una representación "edulcorada" de la vida en el campo que presentaba a la llanura pampeana como un espacio alegre, armonioso y pacífico. El "gaucho" en las escuelas fue adoptando un rol de maestro consejero que -correcciones y omisiones mediantes- apuntaba no solo a determinar pautas de conducta para la niñez ante el estudio sino que se posicionaba como modelo de patriotismo a destacar para hacer de las estudiantes y los estudiantes "hombres dignos de esta patria".

El folklorista Ismael Moya sintetizó su tradicionalismo y su profesión docente en un ensayo que presentó la versión pedagógica del Martín Fierro. La intervención del criollista evidenció el abanico de posibilidades que se condensaba en la figura del gaucho. En efecto, los versos de Fierro funcionaron como usina disparadora de conclusiones, moralejas, recomendaciones y consejos. Las reflexiones proyectadas hacia los alumnos y las alumnas no se correspondieron linealmente al texto original escrito por Hernández. Por el contrario, la mediación de Moya le imprimió su huella indisoluble a los versos cantados por el gaucho. Esa reconfiguración, le permitió al "matrero del desierto pampeano" colocarse el traje de maestro y elucubrar la mejor lección para la niñez interpelada: el amor a la patria.

\section{Referencias}

Amuchástegui, Martha. (1995). Los rituales patrióticos en la escuela pública. En Adriana Puiggrós (dir.), Discursos pedagógicos e imaginario social en el peronismo (19451955), (13-41). Buenos Aires: Editorial Galerna.

Anderson, Benedict. (2001). Comunidades imaginadas: reflexiones sobre el origen y la difusión del nacionalismo. México: Fondo de Cultura Económica. 
Ansaldi, Waldo. (2008). El imperialismo en América Latina. En Historia General de América Latina VII. Los proyectos nacionales latinoamericanos: sus instrumentos y articulación, 1870-1930. París: Unesco.

Bastianini, René. (1943). Autores modernos I, texto de lectura para primer año del ciclo básico. Buenos Aires: Librería del Colegio.

Béjar, María Dolores. (1983). Uriburu y Justo: el auge conservador (1930-1935). Buenos Aires: Centro Editor de América Latina.

Bernárdez Jacques, Elbio. (1945). Fisonomías gauchescas. Buenos Aires: Ferrari Hermanos.

Bordato, E. y M. Rivero. (1943). El español en los maestros, antología y ejercicios. Buenos Aires: Talleres Gráficos de Provendas.

Brumana, Herminia. (1939). Nuestro hombre. Buenos Aires: Talleres Gráficos Argentinos.

Cantonnet, María Ester. (1969). Las vertientes de Javier de Viana: ensayo. Montevideo: Editorial Alfa.

Casais, Norberto. (2008). Ricardo Gutiérrez: médico, soldado y poeta. Buenos Aires: Dirección General Patrimonio e Instituto Histórico.

Casas, Matías. (2012). Las Bases de la tradición. El rol de la Agrupación Bases en la consolidación del gaucho como símbolo nacional. Provincia de Buenos Aires, 1939. Cuadernos del Sur: Historia, (39), 55-72.

Cattaruzza, Alejandro y Eujanian. Alejandro. (2003). Héroes patricios y gauchos rebeldes. En Alejandro Cattaruzza y Alejandro Eujanian (Eds.), Políticas de la historia, Argentina 1860-1960 (pp. 271-262). Buenos Aires: Alianza Editorial.

Coni, Emilio. (1969). El gaucho, Argentina, Brasil, Uruguay (2ª ${ }^{\mathrm{a}}$ Ed.). Buenos Aires: Solar / Hachette.

Corti Videla, Alberto. (1926). Apreciaciones sobre el Martín Fierro. Nativa, revista mensual ilustrada, (34), 11-20.

Darnet de Ferreyra, Ana. (1957). República. Libro de lectura para sexto grado. Buenos Aires: Ángel Estrada y Cia. Editores.

De Millán, Adelina. (1940). Canto al trabajo. Buenos Aires: Kapelusz.

De Viana, Javier. (24 de abril, 1937). La agonía del árbol gaucho. En Caras y Caretas, p. 101.

De Villarino, María. (1957). Nuevas coplas de Martín Fierro. Buenos Aires: Editorial Guillermo Kraft.

Devoto, Fernando. (2001). El revés de la trama: políticas migratorias y prácticas administrativas en la Argentina (1919-1949). Desarrollo económico, 41(162), 281-304. 
Donoso Romo, Andrés. (2010). La Nación como protagonista de la educación en América Latina. Revista Historia de la Educación Latinoamericana, (14), 239-266.

El niño y la escuela para quinto grado. (14 de mayo, 1938). Caras y Caretas, p. 128.

El niño y la escuela para quinto y sexto grados. (24 de setiembre, 1938). Caras y Caretas, p. 123.

Escudé, Carlos. (1990). El fracaso del proyecto argentino. Buenos Aires: Editorial Tesis.

Escuelas Pías Argentinas. (1940). Brisas. Libro de lectura para segundo grado. Buenos Aires: Kapeluzs.

Fernández Bravo, Álvaro. (2006). Celebraciones centenarias: nacionalismo y cosmopolitismo en las conmemoraciones de la independencia. Buenos Aires 1910 - Río de Janeiro 1922. En Andermann, Jens y Beatriz González Stephan. Galerías del progreso: museos, exposiciones y cultura visual en América Latina. Rosario: Ediciones Culturales.

Finocchio, Silvia. (2009). La escuela en la historia argentina. Buenos Aires: Edhasa.

García, María Isabel. (1957). Clarinadas. Libro de lectura para quinto grado. Buenos Aires: Luis Lasserre y Cia. Editores.

Guemes y sus gauchos para $2^{\circ}$ grado. (25 de junio, 1938). Caras y Caretas, p. 154.

Güiraldes, Ricardo. (1926). Don Segundo Sombra. Buenos Aires: Francisco A. Colombo.

Halperín Donghi, Tulio. (1985). José Hernández y sus mundos. Buenos Aires: Editorial Sudamericana.

Hernández, José. (1879). El gaucho Martín Fierro. Buenos Aires: Librería del Plata.

La Pampa para 3er grado. (4 de junio, 1938). Caras y Caretas, p. 131.

Lampérière, Annick. (1995). Los dos centenarios de la independencia mexicana (1910-1921) de la historia patria a la antropología cultural. Historia Mexicana, 45(2), 317-352.

Lvovich, Daniel. (2004). Nación e imaginación. En Esteban Vernik (Ed.), Qué es una nación, la pregunta de Renan revisitada (pp. 65-80). Buenos Aires: Prometeo.

Mantovani, Juan. (2012). Bachillerato y formación juvenil. La Plata: UNIPE Editorial Universitaria.

Martí, José. (1883). Agrupamiento de los pueblos de América. Escuela en Buenos Aires. Buenos Aires, París y Nueva York. En Juan Marinello (Ed.), Nuestra América (pp. 187190). Caracas: Fundación Biblioteca Ayacucho.

Míguez, Eduardo. (2005). El mundo de Martín Fierro. Buenos Aires: Eudeba. 
Moya, Ismael. (1946). El refranero de Martín Fierro. En El Monitor de la Educación Común (pp. 51-73). Buenos Aires: Ministerio de Educación.

Ortemberg, Pablo. (2014). Los centenarios patrios en la construcción de alianzas y rivalidades internacionales: los festejos trasandinos de 1910, la estatua de O'Higgins y los bemoles peruanos. Jahrbuch für Geschichte Lateinamerika, (51), 329-350.

Pérez Montfort, Ricardo. (1999). Un nacionalismo sin nación aparente. La fabricación de lo "típico" mexicano 1920-1950. Política y Cultura, (12), 177-193.

Pougens de Martínez, Guillermina. (1942). Tierra pobre...tierra rica. Buenos Aires: Editorial Independencia.

Puiggrós, Adriana (Dir.). (1995). Discursos pedagógicos e imaginario social en el peronismo (1945-1955). Buenos Aires: Editorial Galerna.

Rogers, Geraldine. (2008). Caras y Caretas. Cultura, política y espectáculo en los inicios del siglo XX argentino. La Plata: EDULP.

Sarlo, Beatriz y Gramuglio, María Teresa (comps.). (1980). Leumann, Borges, Martínez Estrada: Martín Fierro y su crítica, antología. Buenos Aires: Centro Editor de América Latina.

Stancanelli, César. (2009). Martín Fierro: sabiduría, liberación y canto sapiencial: reflexiones para una lectura antropológica filosófica del Martín Fierro. Buenos Aires: Editorial Dunken. 